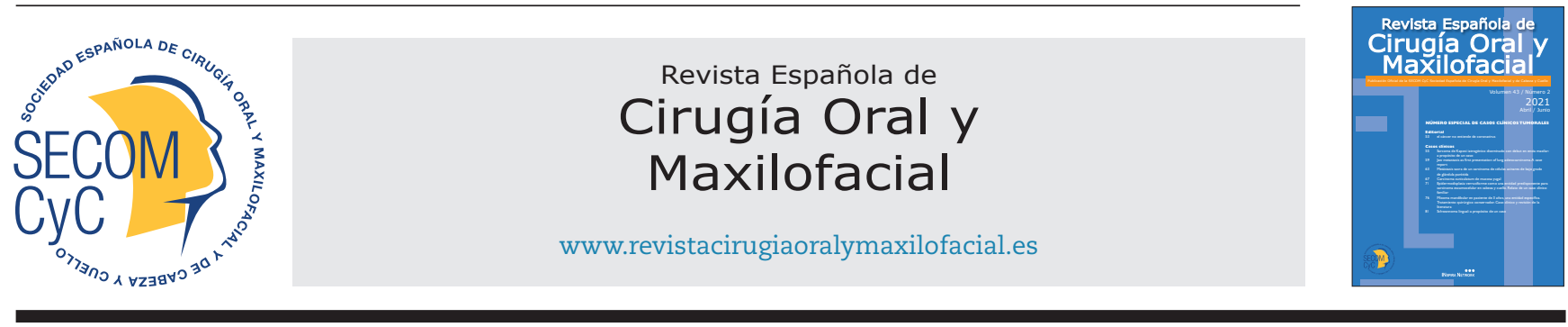

Caso clínico

\title{
Sarcoma de Kaposi iatrogénico diseminado con debut en encía maxilar: a propósito de un caso
}

\section{Marc Agea Martínez, Manuel Tousidonis Rial, Carlos Navarro Cuéllar, Raúl Antúnez-Conde, Dafne Gascón Alonso y José Ignacio Salmerón Escobar}

Servicio de Cirugía Oral y Maxilofacial, Hospital General Universitario Gregorio Marañón. Madrid, España

INFORMACIÓN DEL ARTÍCULO

Historia del artículo:

Recibido: 6 de mayo de 2020

Aceptado: 13 de julio de 2020

Palabras clave:

Sarcoma de Kaposi, Kaposi iatrogénico, enfermedad periodontal, trasplante renal, granuloma piogénico.

\section{R E S U M E N}

El sarcoma de Kaposi es una neoplasia multifocal de células derivadas del endotelio linfático infectadas por el virus del herpes humano 8. Se describen cuatro subtipos clínicos, indistinguibles histológicamente, que difieren en epidemiología y pronóstico: el clásico, el iatrogénico, el endémico y el epidémico. La afectación de la cavidad oral es infrecuente en el tipo iatrogénico y excepcional como debut clínico. El diagnóstico precisa de confirmación histológica con inmunohistoquímica. La afectación oral se asocia a enfermedad diseminada, siendo la sospecha diagnóstica y la toma de biopsia fundamental para el diagnóstico temprano y el correcto estadiaje, debido a las importantes implicaciones terapéuticas y pronósticas.

Se describe el caso clínico de un varón de 41 años de edad valorado por una tumoración en encía adherida con tratamiento periodontal previo y antecedente de trasplante renal. Se realizó biopsia escisional con diagnóstico de SK, que tras completar estudio confirmó SK diseminado tipo iatrogénico, precisando cambio de medicación inmunosupresora y 6 ciclos de tratamiento quimioterápico con respuesta completa.

Disseminated iatrogenic Kaposi's sarcoma with debut in the maxillary gingiva: a case report

\section{A B S T R A C T}

Keywords:

Kaposi sarcoma, iatrogenic Kaposi, periodontal disease, kidney trasplant, pyogenic granuloma.
Kaposi's Sarcoma (KS) is a multifocal neoplasm of cells derived from the lymphatic endothelium infected with the Human Herpes Virus 8 (HHV-8). Four clinical subtypes are described, which are histologically indistinguishable, differ in epidemiology and prognosis: classic, iatrogenic, endemic and epidemic. Involvement of the oral cavity is rare in the iatrogenic type and exceptional as a clinical debut. The diagnosis requires histological confirmation with

\footnotetext{
${ }^{*}$ Autor para correspondencia:

Correo electrónico: ageamarc@gmail.com (Marc Agea Martínez).

DOI: $10.20986 /$ recom.2020.1158/2020
}

1130-0558/@ 2021 SECOM CyC. Publicado por Inspira Network. Este es un artículo Open Access bajo la licencia CC BY-NC-ND (http://creativecommons.org/licenses/by-nc-nd/4.0/). 
immunohistochemistry. Oral involvement is associated with disseminated disease, with diagnostic suspicion and biopsy taking being essential for early diagnosis and correct staging, due to the important therapeutic and prognostic implications.

The clinical case of a 41-year-old male evaluated for a tumor in the attached gingiva with previous periodontal treatment and a history of kidney transplantation is described. Excisional biopsy was performed with a diagnosis of KS, which after completing the study confirmed disseminated iatrogenic-type $\mathrm{KS}$ requiring a change in immunosuppressive medication and 6 cycles of chemotherapy treatment with complete response.

\section{INTRODUCCIÓN}

El sarcoma de Kaposi (SK) es una enfermedad sistémica y maligna que surge de la hiperproliferación endotelial derivada de la infección por el virus del herpes humano 8 (VHH-8) ${ }^{1}$. La patogenia completa del SK se desconoce; en este sentido, la infección por VHH-8 es esencial pero insuficiente, siendo la inmunosupresión el factor principal para el desarrollo y la progresión de la enfermedad.

Se distinguen cuatro subtipos clínicos: el clásico o esporádico, inicialmente descrito por Kaposi y de comportamiento más benigno; el endémico o africano, que suele afectar a una población más joven, el epidémico o asociado al virus de la inmunodeficiencia humana (VIH), el cual es el más frecuente a nivel mundial pero que su incidencia ha descendido gracias a la terapia antirretroviral de gran actividad (TARGA) y, por último, el subtipo iatrogénico, que se relaciona la inmunodepresión y que presenta un aumento en su incidencia considerable en los últimos años ${ }^{1-4}$.

Estos cuatro subtipos comparten la misma afectación clínica en diferentes grados de severidad. Suelen presentar lesiones mucocutáneas que evolucionan progresivamente desde lesiones maculosas hasta nódulos. También pueden afectarse los ganglios linfáticos y los órganos internos sin relación sincrónica con la afectación cutánea. La afectación de la cavidad oral es infrecuente en el SK, más aún en el subtipo iatrogénico ${ }^{1,3,5}$.

\section{CASO CLÍNICO}

Varón de 41 años sin reacciones alérgicas medicamentosas ni hábitos tóxicos, con antecedentes de trasplante renal e hipertensión arterial y en tratamiento con prednisona, tacrolimus, ácido micofenólico, carvedilol y amlodipino.

Es derivado para valoración de una tumoración no dolorosa (0/10 EVA), de 2 meses de evolución, en encía del maxilar tras fracaso de tratamiento periodontal previo, con clínica de sangrado con el cepillado y sin síntomas B. A la exploración se apreció una tumoración exofítica hiperqueratósica, de color rojo-violácea, de bordes bien definidos y de 1-1,5 cm de diámetro en encía adherida entre piezas 21 y 11 (Figura 1). No ocasionaba movilidad dentaria ni se palpaban adenopatías cérvico-faciales. La ortopantomografía (OPG) descartaba afectación ósea y dental. En el diagnóstico diferencial se incluyó: el granuloma piógeno, las afecciones granulomatosas, las lesiones vasculares, el linfoma, la angiomatosis bacilar y el SK,

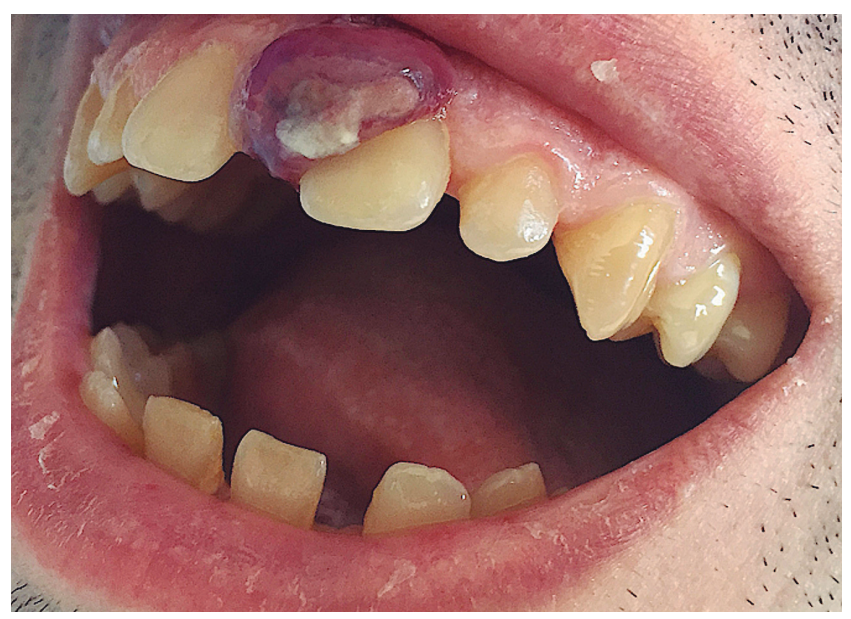

Figura 1. Tumoración exofítica hiperqueratósica, rojo-violácea, de bordes bien definidos, de 1 x 1,5 cm en encía adherida entre piezas 21 y 11.

motivo por el cual se decidió realizar exéresis de la lesión y reconstrucción con colgajo local de encía vestibular libre.

El estudio histológico reveló una proliferación neoplásica por células fusocelulares atípicas con actividad Ki67 del $60 \%$ y tinción intensa con CD34 y HHV-8, confirmando el diagnóstico de SK (Figura 2).

Tras la confirmación se completó el estudio con una tomografía computarizada (TC), evidenciándose afectación diseminada pulmonar bilateral, así como ganglionar cervical, subcarinal, hepática, retroperitoneal e ilíaco-inguinal (Figura 3). El

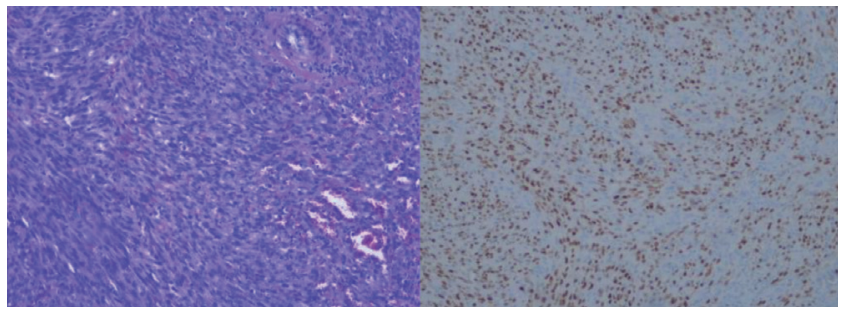

Figura 2. A: Histología con hematoxilina y eosina: proliferación de células fusocelulares atípicas con actividad proliferativa Ki67 y actividad CD34. B: tinción positiva para HHV-8. 


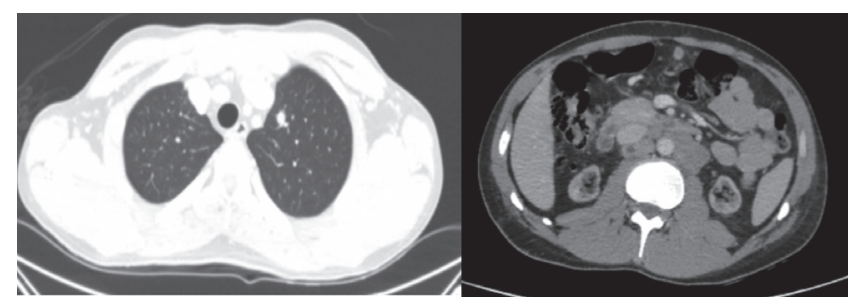

Figura 3. Afectación ganglionar supra e infradiafragmática.

estudio serológico descartó infección por VIH y presentó positividad para HHV-8, confirmando el diagnóstico de SK subtipo iatrogénico diseminado.

Ante este diagnóstico, el tratamiento del paciente tuvo que verse modificado, recibiendo 6 ciclos de doxorrubicina liposomal pegilada (PLD) y sustituyendo la medicación inmunosupresora (tacrolimus y ácido micofenólico por everolimus).

Durante el seguimiento, se comprobó la correcta cicatrización de la herida intraoral con buena adaptación del colgajo de encía (Figura 4). Tras finalizar el tratamiento quimioterápico el paciente obtuvo una respuesta completa, sin evidencia de recidivas durante el periodo de seguimiento (12 meses).

\section{DISCUSIÓN}

La finalidad de este artículo es dar a conocer que el SK es una neoplasia infrecuente, que conlleva una gran dificultad de diagnóstico y que debemos tenerla presente en determinados pacientes.

En la actualidad, la TARGA ha disminuido el número de casos en paciente VIH, mientras que la incidencia del SK subtipo iatrogénico ha aumentado en los países desarrollados, secundario al aumento de pacientes trasplantados. El riesgo de SK en receptores de trasplante de órganos es de 50 a 500 veces mayor en comparación con la población general, siendo el trasplante renal el de mayor incidencia y presen-

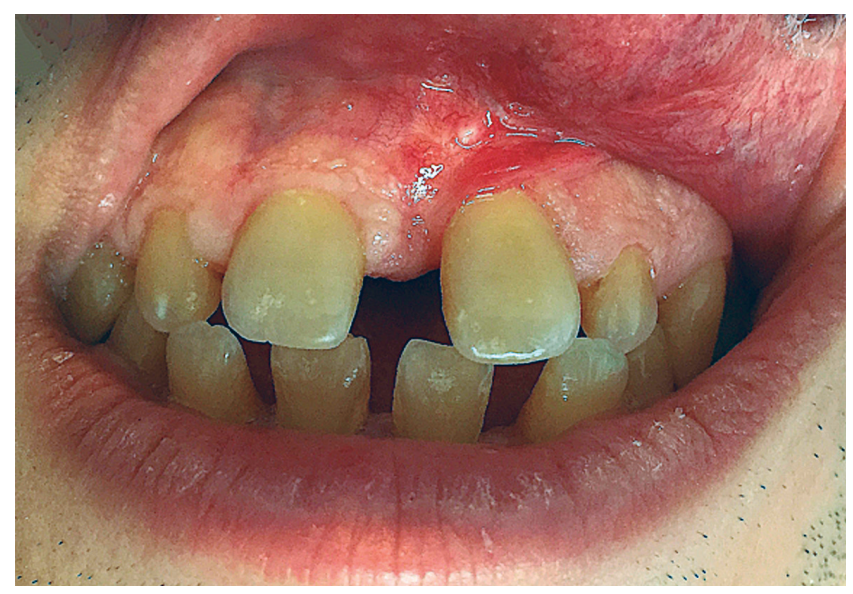

Figura 4. Cicatrización a los 14 días tras la exéresis quirúrgica. tando un pico en los primeros 2 años tras el trasplante. El riesgo aumenta con la edad del receptor (afecta sobretodo a varones mayores de 45 años), con el número de desajustes en el locus HLA-B y con un régimen inmunosupresor más agresivo, como sucede en nuestro caso ${ }^{1}$. La mayoría de los casos de SK después del trasplante se desarrollan como resultado de la reactivación de VHH-8, tal como ocurrió con el caso del paciente presentado ${ }^{1}$.

Las manifestaciones orales son muy infrecuentes (2\%), sobre todo como clínica de debut. Suelen localizarse en mucosa de paladar, encía y lengua ${ }^{6}$. Cuando existen lesiones nodulares intraorales, se considera una enfermedad avanzada debido a la frecuente relación sincrónica con una afectación sistémica de mayor/menor grado, como sucede en nuestro paciente ${ }^{2}$. La prueba de elección para el diagnóstico de SK es la detección del virus en una muestra histológica y, tras ello, confirmar el diagnóstico con una serología vírica y realizar las pruebas complementarias necesarias para valorar una posible enfermedad diseminada y su etiología ${ }^{1}$.

Las terapias para el SK han evolucionado durante los últimos años obteniendo un gran abanico de posibilidades. Se realiza de forma individualizada en función del subtipo de SK, las características del paciente, la gravedad y la extensión de la enfermedad. En casos como el del paciente presentado, que recibe tratamiento inmunosupresor, la literatura científica expone la necesidad de realizar una sustitución de la terapia inmunosupresora a everolimus o sirolimus. Además, en pacientes con enfermedad diseminada y/o visceral, se recomienda tratamiento sistémico con doxorrubicina liposomal pegilada (PLD) o paclitaxel (PCT) $)^{1,7}$.

Actualmente, se están desarrollando tratamientos que actúan específicamente contra VHH-8 y/o contra factores angiogénicos, como la lenalidomida, el bevacizumab o la pomalidomida, con resultados prometedores pero que aún están en fases de estudio precoces.

Finalmente, destacamos la necesidad de un correcto diagnóstico del SK. Es de vital importancia tener la sospecha de infecciones oportunistas y sospechar el SK iatrogénico para poder realizar un adecuado diagnóstico diferencial ante pacientes con tratamiento inmunosupresor y lesiones mucocutáneas (incluidas las de cavidad oral) de nueva aparición. La biopsia de la lesión y el estudio serológico, junto con un estudio de imagen complementario son esenciales para el diagnóstico y estadificación de la enfermedad.

\section{RESPONSABILIDADES ÉTICAS}

Los autores declaran que en este artículo se ha realizado respetando las recomendaciones de la Declaración de Helsinki de 2013.

\section{B I B L I O G R A F Í A}

1. Lebbe C, Garbe C, Stratigos AJ, Harwood C, Peris K, Marmol V del, et al. Diagnosis and treatment of Kaposi's sarcoma: European consensus-based interdisciplinary guideline (EDF/EADO/ EORTC). Eur J Cancer. 2019;114:117-27. DOI: 10.1016/j. ejca.2018.12.036. 
2. Fatahzadeh M. Kaposi sarcoma: Review and medical management update. Oral Surg Oral Med Oral Pathol Oral Radiol. 2012;113(1):2-16. DOI: 10.1016/j.tripleo.2011.05.011.

3. Shetty K. Disseminated oral Kaposi sarcoma lesion with extensive visceral involvement. Oral Oncol Extra. 2006;42(1):1821. DOI: 10.1016/j.ooe.2005.08.003.

4. Pantanowitz L, Khammissa RAG, Lemmer J, Feller L. Oral HIVassociated Kaposi sarcoma. J Oral Pathol Med. 2013;42(3):201-7. DOI: 10.1111/j.1600-0714.2012.01180.x.
5. Garzino-Demo P, Mettus A, Passalacqua F, Vittone F, Ramieri G Oral Localization of Kaposi Sarcoma: Clinical Presentation and Conservative Management. J Craniofac Surg. 2017;28(6):e545-7. DOI: $10.1097 /$ SCS.0000000000003838.

6. Faden A, AlSheddi M, AlKindi M, Alabdulaaly L. Oral Kaposi Sarcoma in HIV-seronegative Saudi patient: Literature review and case report. Saudi Dent J. 2017;29(3):129-34. DOI: 10.1016/j. sdentj.2017.03.003.

7. Mra Z, Chien J. Kaposi's sarcoma of the tongue. Otolaryngol Head Neck Surg. 2000;123(1 I):151. DOI: 10.1067/mhn.2000. 104776. 